\title{
Fazendo aulas de ecologia em campo: vendo conceitos de Ecologia
}

\author{
Taking ecology classes in the field: seeing Ecology concepts \\ Tomando clases de ecología en el campo: ver conceptos de Ecologia
}

Recebido: 17/12/2021 | Revisado: 24/12/2021 | Aceito: 29/12/2021 | Publicado: 07/01/2022

\author{
Antonio Batista Pereira \\ ORCID: https://orcid.org/0000-0003-0368-4594 \\ Universidade Federal do Pampa, Brasil \\ e-mail: anbatistape@gmail.com. \\ Betina Kappel Pereira \\ ORCID: https://orcid.org/0000-0001-5665-6234 \\ Universidade La Salle, Brasil \\ E-mail: betinakappe111602@gmail.com
}

\begin{abstract}
Resumo
Este trabalho apresenta uma proposta metodológica para o ensino-aprendizagem de ecologia através de atividade de campo, na forma de um roteiro para realização de trabalho prático de observações em campo. O roteiro foi elaborado para orientar as aulas práticas em campo, uma vez que estas geralmente são bastante dispersivas, devido a grande motivação dos alunos e a diversidade de desafios para aprendizagem que lhe é proporcionado. Com o objetivo de oferecer ao aluno situações de experiência que contribuíssem para a construção de conhecimento em ecologia foi proposta esta metodologia buscando dinamizar e otimizar a construção do conhecimento. O roteiro foi aplicado com seis turma de acadêmicos dos cursos de biologia e utilizando métodos qualitativos são apresentados e discutidas as principais observação aferidas no desenvolvimento das aulas.
\end{abstract}

Palavras-chave: Aulas práticas; Ambiente natural; Biologia; Metodologia.

\begin{abstract}
This paper presents a methodological proposal for the teaching-learning of ecology through field activity, in the form of a script for carrying out practical work of field observations. The script was designed to guide practical classes in the field, as these are usually quite dispersive, due to the high motivation of students and the diversity of learning challenges that are provided. In order to offer the student experience situations that contribute to the construction of knowledge in ecology, this methodology was proposed, seeking to streamline and optimize the construction of knowledge. The script was applied with six class of academics from biology courses and using qualitative methods the main observations measured in the development of classes are presented and discussed.
\end{abstract}

Keywords: Practical classes; Natural environment; Biology; Methodology.

\section{Resumen}

Este trabajo presenta una propuesta metodológica para la enseñanza-aprendizaje de la ecología a través de la actividad de campo, en forma de guión para la realización de trabajos prácticos de observaciones de campo. El guión fue diseñado para orientar las clases prácticas en el campo, ya que estas son generalmente bastante dispersas, debido a la alta motivación de los estudiantes y la diversidad de desafíos de aprendizaje que se brindan. Con el fin de ofrecer al alumno situaciones vivenciales que contribuyan a la construcción del conocimiento en ecología, se propuso esta metodología, buscando agilizar y optimizar la construcción del conocimiento. El guión fue aplicado com seis clases académicos de cursos de biología y utilizando métodos cualitativos se presentan y discuten las principales observaciones realizadas en el desarrollo de las clases.

Palabras clave: Clases prácticas; Medio natural; Biología; Metodología.

\section{Introdução}

Este trabalho apresenta e discute uma proposta metodológica para fazer aulas de ecologia em campo, o qual foi iniciado em meados de 1980, quando passou-se a utilizar tal método. Dentre os fatos que levaram a buscar novas metodologias para o ensino-aprendizagem nas diferentes áreas da biologia emergiu principalmente a fatos tais com:

- Eram jovens professores formados em uma escola cuja base das experiências formativas era a prática, a qual deveria ser teorizada após cada observação, tal forma de fazer aulas foi logo muito valorizada, uma vez que vivia-se o auge das feiras de Ciência (Pereira et al. 2000; Piaget, 1972 e 1975). 
- A necessidade de uma identidade profissional levou a busca de um entendimento claro do "sujeito professor", sobre o ambiente de trabalho e como fazer o melhor. Tal entendimento levou a busca do significado da Educação, para a construção de um conceito, chegando-se a Ferreira (1999), no qual entre as várias conotações escritas, a atenção voltou-se: "Educação é o ato de educar-se", tal surpresa deveu-se principalmente a simplicidade e por aparentemente não dizer muito. Como o autor é muito conceituado e este dicionário é uma referência na língua brasileira, logo o problema não está no texto, mas em que está lendo. Então constatou-se que a importância deste conceito está na palavra educar-se, logo não é o professor que ensina é o aluno que aprende.

Para que o conceito de educação escolhido fosse seguido, ter-se-ia que construir uma forma de fazer aulas, que proporcionasse ao aluno experiências para ele educar-se. Logo, como em todo o plano de ensino os objetivos são muito importantes, buscou-se a elaboração dos mesmo de forma que atendessem este conceito, então decidiu-se pela expressão "Proporcionar situações de experiências para que os alunos construam seus conhecimentos sobre:" Esta passou a fazer parte de qualquer plano de ensino ou de trabalho de campo, aparecendo pela primeira vez na bibliografia em Pereira (1993), e depois em Pereira e Putzke (1996).

Ao ler em Comenios (1957), que "quase sempre o professor toma o aluno tal qual encontra, e começa logo a torneálo, a batê-lo, a torcê-lo, a modelá-lo a seu modo, pretendendo que ele se torne imediatamente uma beleza, uma jóia, e, se o não consegue logo (e como seria possível consegui-lo?), enche-se de ira, indigna-se, enfera-se”. E havemos de admirar-nos que haja quem critique e fuja de semelhante método de educação? Deve-se antes admirar-se que haja ainda quem se entregue à tais educadores. E foi então, para fugir deste modelo que iniciou-se elaboração de roteiros para prática de campo e de laboratório.

A utilização da prática como a base inicial não é nova, pois Comenios (1957), escreveu na primeira edição de sua Didática Magna, em 1536, que "o conhecimento necessariamente deve principiar pelos sentidos (uma vez que nada se encontra na inteligência, que primeiro não tenha passado pelos sentidos). Por que é, então, que o ensino tenha que principiar por uma exposição verbal das coisas, e não por uma observação real dessas mesmas? Somente depois da observação das terem sido feitas virá a palavra para explicar melhor."

Nesta forma de abordagem dos objetos do conhecimento, conforme Altet, (2001), as aulas iniciam pela prática, segue-se a teoria, a análise e a prática novamente. Entretanto, a prática sempre deve levar à teoria, pois para Charlier (2001), a prática não é espontaneamente didática. Para ser formadora, ela deve ser teorizada. Portanto, nestas propostas metodológicas as habilidades à ser desenvolvidas a partir da prática em laboratório ou no campo, sempre seguidas ou acompanhadas pela teorização. Então, a prática é o meio pelo qual o aluno constrói seus conhecimentos sobre o assunto, ao contrário daqueles que fazem com que as práticas de laboratório sejam o momento em que os alunos realizam um trabalho para encerrar com "chave de ouro" a unidade estudada, através de aulas teóricas. Poder-se-á dizer, portanto, que o professor leva os alunos ao laboratório para assistir a um filme que já lhes foi contado em aula teóricas (Perrenoud, 1998 e 2013).

A origem e evolução das diferentes áreas da Filosofia, basearam-se principalmente no estudo das relações do homem com a natureza. Depois surgiu o estudo das relações interpessoais e, finalmente, o estudo das relações entre o homem e a história. No entanto, cabe destacar que nessa evolução foram negligenciados os estudos práticos do ambiente e das relações entre homem e o meio em que vive, afastando o homem do seu hábitat e levando-o a ser o grande responsável pelas catástrofes e agressões ambientais prejudiciais à qualidade de vida (Pereira, 1993).

A proposta não é nova nem inédita, pois, como escreve Terradas (1978), o trabalho de campo é uma tradição a ser recuperada no ensino das Ciências Naturais, e esta metodologia é a base pedagógica da escola ativa. Estes autores acreditam que o ensino fundamentado apenas em livros didáticos e exposições teóricas contribuiu significativamente para a formação de profissionais e líderes desvinculados da realidade social em que vivemos. 
As aulas práticas em campo tem demonstrado serem muito eficientes para o desenvolvimento de habilidades para um melhor entendimento dos ambientes, a qual é fundamental para a compreensão do ecossistema em que vivemos, levando as pessoas a compreenderem melhor e praticarem a Educação Ambiental e a Alfabetização Ambiental, esta última ainda pouco conhecida no Brasil. Isto deve-se principalmente à utilização de uma metodologia ativa, o que facilita a análise e interpretação do ambiente e do habitat vivido pelo indivíduo, uma vez que o homem valoriza o conhecido e tem medo do desconhecido (Gomes et al., 2021; Sousa et al., 2021; Marcinkowski, 1998 e Coyle, 2005).

Para Pereira e Putzke (1996), a experiência acadêmica nos cursos de Biologia tem demonstrado que os trabalhos de campo são muito importantes, principalmente nos primeiros semestres do curso, quando o aluno motiva-se e ambiciona um novo universo de conhecimentos. É neste momento que o aluno passará a gostar ou desgostar do curso que escolheu, e então pode-se utilizar esta atividade para motivá-lo reduzindo significativamente a evasão, principalmente nas universidades privadas.

Com o objetivo de sugerir aos professores de ecologia e ciências biológicas formas mais dinâmicas para aulas práticas em campo, compartilhamos esta proposta metodológica, que foi muito bem aceita pelos acadêmicos.

\section{Material e Métodos}

Este trabalho utiliza um método qualitativo exploratório do tipo estudo de caso, conforme Gil (2008), o qual se aplica para situações observadas em contexto real. O planejamento dos roteiros para as atividades de campo em ecologia, baseou-se em métodos e técnica que proporcionasse ao aluno vivenciar situações de experiências que estivessem contextualizadas em seus ambientes, possibilitando a construção e redescoberta de assuntos e temas que foram estudados.

Em um segundo momento foram escolhidos os temas a serem abordados os quais faziam parte do plano de ensino do curso de Ciências Biológicas, conforme objetivos propostos nos mesmos e as referências bibliográficas e textos a serem utilizados para o preparo e a execução das atividades previstas nos roteiros.

\subsection{Justificativas para realização do trabalho}

As justificativas para a proposição da atividade prática "Vendo conceitos de Ecologia" emergem de fatos tais como:

- a forma exageradamente acadêmica de fazer aulas de Ecologia tem levado a valorização excessiva dos conteúdos em detrimento da sua aplicação ou da presença dos mesmos na vida das pessoas;

- a prática no trabalho com alunos têm demonstrado que o aluno não aprende apenas ouvindo, ou pelo menos o nível do ensino e aprendizagem apresenta níveis insignificantes;

- esta técnica de abordagem dos conteúdos tem sido feitas com frequência, apresentando aproveitamento excelente dos aluno na construção de seus conhecimento de forma alegre e descontraída;

- a técnica de ensino que inicia pela prática tem demonstrado maior eficiência na aprendizagem dos alunos.

\subsection{Objetivo do trabalho de campo}

O roteiro "Vendo conceitos de Ecologia" tem como objetivo principal proporcionar um conjunto de situações de experiências que possibilitem aos alunos:

- desenvolver a capacidade de relacionar os fenômenos naturais com os conceitos e leis apresentados na bibliografia, através da observação orientada e a teorização dos dados coletados;

- redescobrir uma das maneiras mais fáceis e agradáveis de compreender os conteúdos teóricos, desenvolvendo o raciocínio e o espírito crítico, através da prática de comparação dos fenômenos e leis observadas com o que está descrito na bibliografia; 
- revisar os conceitos gerais de ecologia, iniciando pela prática e teorizando as observações, através da observação, da leitura do conceito e sua localização na natureza;

- vivenciar técnicas de avaliação de relações entre os seres vivos, para iniciação da compreensão do significado de impacto ambiental, através de alterações geralmente encontradas no ambientes onde a aula é feita;

- redescobrir o ambiente e os ecossistemas com o principal laboratório para aprender biologia, através de observações e teorização dos dados obtidos.

\subsection{Execução do trabalho}

Baseando-se principalmente em Pereira e Putzke (2010), Dajoz (1983), Odum (1983), Krebs (1994), Watanabe (1987) e Smith e Smith (1998), reúne os conceitos de: a. Ecologia, b. habitat, c. nicho, d. competição, e. predação, f. simbiose, g. parasitismo, h. mutualismo, i. população, j. comunidade, k. ecossistema, 1. bioma e m. biosfera.

Antes do deslocamento para o local de realização do trabalho foi muito importante destacar as justificativas, os objetivos do trabalho e aferir com os alunos os conceitos e conteúdos a serem estudados na atividade de campo.

\subsection{Atividades sugeridas}

1. Localizar, observar e descrever locais, fenômenos ou fatos onde é possível visualizar os conceitos de Ecologia, habitat, nicho, competição, predação, simbiose, parasitismo, mutualismo, população, comunidade, ecossistema, bioma e biosfera respectivamente.

\section{Resultados e Discussão}

As observações dos conceitos iniciaram pelo de ecologia, cuja conotação foi: "Ecologia é a ciência que trata das relações entre os seres vivos e/ou entre eles o ambiente". Nas observações orientadas pelo professor as folhas de planta foram as mais visualizadas, principalmente as marcas deixadas por insetos que as utilizam como alimento foram discutidas, além herbívoro pastando, nestes fatos os alunos afirmaram terem visto claramente o conceito de ecologia, pois o animal está relacionando-se com a planta para alimentar-se. Como a prática não é pedagógica por si só ela deve ser teorizada, ao fazer isto pode-se constatar que a principal forma de relação entre os seres vivos é o trofismo, a alimentação. Desta forma o alunos aprendeu mais do que a proposta inicial.

Ao buscar a observação de um hábitat a partir do conceito de que "hábitat é o ambiente que oferece as condições necessárias e características para a sobrevivência e procriação de uma espécie" as plantas foram as mais observadas por serem as mais abundantes no ambiente, foram listados o solo para árvores e ervas, pedras para liquens e musgos, os quais também foram observados o córtex dos troncos, além de espécies de plantas aquática que não cresciam fora do lago.

A observação de nicho, cujo conceito escolhido foi que "nicho é a função ecológica desempenhada por uma espécie no ecossistema onde vive". Este levou o aluno a buscar mais informações sobre a função de uma espécie em um ecossistema. A principal orientação geralmente feita pelo professor foi a aferição de relações entre os organismos, como as aferidas acima como por exemplo a herbivoria quando o aluno concluía que a função daquela planta no ecossistema era servir de alimento a determinado herbívoro ou um inseto sobre uma flor onde constata-se que o nicho da planta é servir de alimento ao inseto e o nicho do inseto é contribuir com a polinização.

A busca de observações para a ver o conceito de competição no ambiente em que o aluno encontrava-se, a partir do conceito de que "competição é a luta entre dois organismos pela mesma coisa", lista deste abundava como, por exemplo as plantas crescendo em comunidade e competindo pelo substrato, pela luz pelo, pelo espaço, a pessoas competindo pelo ar, pelo emprego ou nos esporte. 
A partir do conceito de que "Predação e a relação alimentar entre organismos de espécies diferentes, benéfica para um deles (predador), à custa da morte e consumo do outro (predado ou presa)", uma das observações feitas com mais frequência foi em uma teia de aranha, na qual eram observados insetos ou restos destes, que foram utilizados pela aranha. Além destes, restos de animais também foram aferidos e em uma oportunidade foi observado um gavião voando com um pequeno roedor presos em suas garras.

Ao buscar a observação do conceito de simbiose constatou-se que para muitos estudantes a conotação deste conceito era o mesmo de mutualismo. Logo buscou-se na literatura o conceito correto de simbiose, "o qual em seu sentido amplo, diz-se da vida em comum entre dois ou mais organismos". O claro entendimento deste conceito facilitou muito sua visualização nos ambientes sendo que a visualização mais fácil foram as plantas epífitas.

A localização de um evento no qual fosse possível a identificação do conceito de parasitismo cujo conceito é "uma associação desarmônica entre dois seres, na qual um deles tira qualquer proveito e acarreta ao outro um prejuízo mais ou menos intenso", logo tomou-se as fitopatologias como observação muito fácil pelos sintomas que abundam na natureza. Porém ao teorizar as observações de fungos parasitas de plantas surgiu a fumagina, cujo sintoma é a cobertura da folha da planta por película preta. No entendimento desta constatou-se que a planta havia sido parasitada inicialmente por um pulgão e como esta espécie produz uma secreção sobre as superfícies parasitadas, e então sobre esta desenvolveu-se o fungo o qual não possui relação trófica com a planta. O parasita era o pulgão e não o fungo.

O mutualismo cujo conceito seguido é "um tipo de associação interespecífica, harmônica e bilateral, fitofítica, fitozóica ou zoozóica, em que se observa uma permuta de favores". Neste, as relações mais observadas foram os insetos e as flores, nos quais os insetos utilizam o néctar e/ou o pólen como alimento contribuem com planta realizando a polinização.

O conceito de população, utilizado em ecologia que é "o número de indivíduos da mesma espécie que ocupa determinada área por determinado tempo", corresponde exatamente ao utilizado com a conotação de populações de uma cidade de um estado de um país ou do planeta terra, esta contextualização facilitou os alunos na construção de seu conceito.

$\mathrm{Na}$ observação de comunidade, cujo conceito utilizado é "o conjunto de populações que convivem em um mesmo ambiente, em uma mesma área em determinado período de tempo, interagindo umas com as outras", foi muito facilitado pelo claro entendimento do conceito de população. Portanto os alunos observavam o ambiente ao seu redor diferenciavam população e construíam claramente seus conceitos sobre comunidade.

Ao discutir o conceito de ecossistema, cujo escolhido foi: "é o nome utilizado para designar a maior unidade da ecologia, sendo que eco significa casa e sistema significa que se trata de uma estrutura organizada incluindo as relações entre os seres vivos que vivem no ambiente referido e entre eles e o ambiente", os acadêmicos ao observarem o ambiente que os rodeavam para visualizar tal conceito, alguns constataram que neste poder-se-ia reunir praticamente todos os conceitos aferidos anteriormente. Identificaram no ecossistema a comunidade que contribuem com os fatores bióticos e listaram também fatores abióticos. Ao observar uma floresta ou um campo identificaram um ecossistema natural e em uma plantação como, por exemplo, milho e reflorestamento, os quais foram identificados como ecossistemas agrícolas.

A busca do conceito de bioma, cujo o escolhido foi "um amplo conjunto de ecossistemas, caracterizados principalmente pelas semelhanças dos tipos fisionômicos da vegetação clímax e pela influência da comunidade animal". Quando o aluno buscava mais informações na literatura sobre este conceito, geralmente constatava que no território brasileiro existem seis biomas (Amazônia, Caatinga, Cerrado, Mata Atlântica, Pampa e Pantanal), tal informação levava-os a relacioná-lo com o ambiente onde viviam, colocando-se em um bioma. Quando isto aconteceu ocorreu a aprendizagem, com uma mudança de comportamento, e eles passaram a defender o bioma no qual viviam. Para os alunos que utilizaram este conceito em um estabelecimento de ensino localizado no Bioma Pampa, construiu-se uma discussão mais intensa e um melhor conhecimento 
deste bioma, o qual foi considerado por alguns como o Bioma esquecido, por ser o menos citado e estudado entre os demais que existem no Brasil.

A biosfera teve como conceito eleito para este trabalho: "o sistema integrado de organismos vivos e seus suportes, compreendendo a camada envolvente do planeta Terra com a atmosfera circundante, estendendo-se para cima e para baixo até onde exista naturalmente qualquer forma de vida". Apesar de ser praticamente impossível visualizar os limites e clara identificação deste conceito, a experiência vivenciada no estudo dos conceitos anterior que levaram o aluno a desenvolver a habilidade de observar e com os dados obtidos buscar na literatura a teorização da prática, não houve dificuldade para que o estudante construísse seu conceito de biosfera.

\section{Considerações Finais}

Esta técnica de ensino-aprendizagem de alguns conceitos de ecologia levou a conclusões como, pro exemplo:

- Os alunos desenvolveram a habilidade de contextualização do conhecimento, o que contribui significativamente com a aprendizagem, uma vez que ele relaciona o conhecimento com algo conhecido tomado como referência.

- Com esta técnica o aluno não memoriza o conhecimento ele o constrói baseando em suas observações e a consulta a bibliografia sugerida para as atividades.

- Pelas discussões e pela mudança de comportamento observada nas aulas foi possível constatar que o aluno passa a valorizar os ambientes onde vive e onde sua comunidade está inserida.

- Nas avaliações das aulas e da atuação do professor feita pelos alunos, demonstraram grande empatia para com o professor e com o método, contribuindo significativamente para elevação do nível de aprendizagem e a redução do índice de reprovação.

- Esta proposta metodológica poderá também ser utilizada para ver os conceitos de ecologia acima propostos em filmes. Estes foram testados em observações no filme "A marcha dos pinguins" (La Marche de l'empereur), o qual apresenta a reproduções do pinguin imperado (Aptenodytes forsteri Gray, 1844) no continente Antártico e praticamente todos os conceitos listados foram vistos pelos alunos.

- Para este trabalho utilizou-se um método qualitativo, uma vez que o principal objetivo é oferecer ao leitor uma forma de utilização desta metodologia, logo o importante não foram números de observações ou nível de aproveitamento dos alunos, e sim o como fazer a aula. Porém pode-se utilizar um método quantitativo para avaliar o nível de aprendizagem comparando os graus obtidos na avaliação dos conteúdos trabalhados, com as medias existentes em histórico escolar do aluno em semestres anteriores, neste caso utiliza-se apenas números para identificação dos mesmos.

\section{Referências}

Altet, M. (2001). As competências do Professor Profissional: entre conhecimentos, esquemas de ação e adaptação, saber analisar. In: Perrnoud, P., Paquay, L., Altet, M. \& Charlier HalieR, É. Formando Professores Profissionais. Quais estratégias? Quais competências? 2 ed. Porto Alegre. Artemed Editora, p. 22-35.

Charlier, É. (2001). Formar Profesores Profissionais para uma formação contínua articulada à Ética. In: Perrenoud, P., Paquay, L., Altet, M. \& Charlier, É. Formando Professores Profissionais. Quais estratégias? Quais competências? (2a ed.), ARTEMED Editora, 85 - 117, 2001.

Comênios, J.A. (1957). Didática Magna - Tratado da Arte Universal de Ensinar tudo a todos. (3a ed.), Fundação Galouste Gulberkian.

Coyle, K. (2005). Environmental literacy in America. Washington. The national Environment Education \& Training Fundation.

Daloz, R. (1983). Ecologia Geral. (4a ed.), Ed. Vozes. 471p.

Ferreira, A.B. de H. (1999). Novo Aurélio, o Dicionário da Língua Portuguesa, Século XXI. (3a ed.), Ed. Nova Fronteira. 2128p.

Gil, A.T. (2008). Métodos e técnicas de pesquisa social. Atlas S.A. (6a ed.), 220 p. 
Research, Society and Development, v. 11, n. 1, e29811124867, 2022

(CC BY 4.0) | ISSN 2525-3409 | DOI: http://dx.doi.org/10.33448/rsd-v11i1.24867

Gomes, K. R. F. P.; Nascimento, S. M.; Lleite, E. F.; Blazquez, A. L. T. \& Rosas, M. L. A. C. (2021). Experiencia docente en la formación inicial del profesorado: contribuciones a la enseñanza de la Educación Ambiental. Research, Society and Development, 10(12): 51101220166.

Krebs, C. J. (1994). Ecology. (4a ed.), Harper Collins College Publishers. 801p.

Marcinkowski, T. (1998). Predictors of responsible environmental behavior: A review of three dissertation studies. In H. Hungerford, W. Bluhm, T. Volk, and J. Ramsey (Eds.), Essential Readings in Environmental Education (pp. 227-256). Champaign, IL: Stipes Pub. Co. Note: A revised version of this article was published in the 2001 edition of Essential Readings (pp. 247-277).

Odum, E. P. (1988). Ecologia. Ed. Guanabara Koogan S.A. 434p.

Pereira, A. B. (1993). Aprendendo Ecologia através da Educação Ambiental. Ed. Sagra-DCLuzzatto. 94p.

Pereira, A. B. \& Putzke, J. (1996.) Proposta Metodológica para o Ensino de Botânica e Ecologia. Ed. Sagra-DC Luzzatto. 184p.

Pereira, A. B.; Oaigen, E. R. \& Hennig, G. J. (2000). Feiras de Ciências. Ed. ULBRA. 287 p.

Pereira, A. B. \& Putzke, J. (2010). Dicionário Brasileiro de Botânica. CRV, 437p.

Perrenoud, P. 1998. Construir as competências desde a escola. (2a ed.), Artmed.

Perrenoud, P. (2013). Desenvolver competências ou ensinar saberes?: A escola que prepara para a vida. Penso.

Piaget, B. J. (1972). A Evolução Intelectual da Adolescência à Vida Adulta. Trad. Fernando Becker e Tania B.I. Marques. Porto Alegre: Faculdade de Educação, 1993. Traduzido de: Intellectual Evolution from Adolescence to Adulthood. Human Development, 15: 1-12.

Piaget, J. (1976). A Equilibração das Estruturas Cognitivas. Problema central do desenvolvimento. Rio de Janeiro: Zahar.

Smith, R. L. \& Smith, T. M. (1998). Elements of Ecology. (4a ed.), Addison Wesley Longman, Icn. 555p.

Sousa, A. F.; Araujo da Silva, J. \& Sudério, F. B. (2021). Uso de metodologias ativas como estratégia no ensino remoto em um curso de Licenciatura em Ciências Biológicas. Research, Society and Development, 10(12): 341101220440.

Terradas, A. (1978). El papel de la educacion ambiental em Amarica Latina. UNESCO. 120 p.

Watanabes, S. (1987). Glossário de Ecologia. Academia de Ciências do Estado de São Paulo. 271p. 